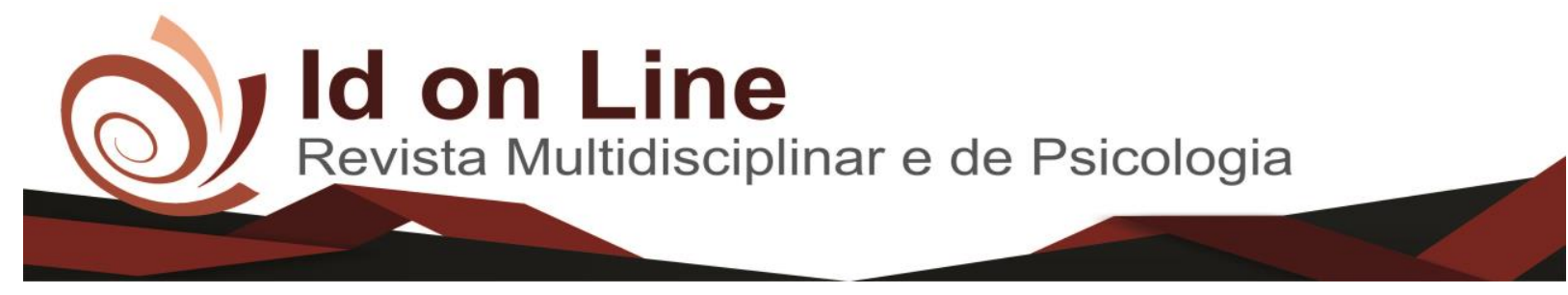

Artigo de Revisão

\title{
A Educação de Surdos: \\ Formação de Professores na Língua Brasileira de Sinais (LIBRAS)
}

Andrea Silva Araújo ${ }^{1}$; Aurelania Maria de Carvalho Menezes² ; Aline Cássia Silva Araújo3 ${ }^{3}$

\begin{abstract}
Resumo: O objetivo desta pesquisa foi identificar, descrever e analisar os artigos científicos relacionados a importância da educação de surdos na formação de professores. Foi realizada uma revisão bibliográfica nas bases de dados de revistas científicas, notas técnicas e monografias, dissertações e teses, em Programas de Graduação em Pedagogia e Pós-Graduação em Letras/Libras, com embase temporal entre 1999 a 2017. Após a investigação da revisão de literatura e leitura do conteúdo, conclui-se que a educação para os surdos foi conquistada com muita luta, principalmente no que se refere ao preconceito, pois, durante muito tempo, os surdos eram considerados pessoas doentes e motivadores de vergonha dentro da familia e da sociedade, com isso, eram comuns encontrar um surdo abandonado. Destaca-se como a primeira escola de surdos, fundada no Brasil, o "Imperial Instituto dos Surdos-Mudos", atualmente, "Instituto Nacional de Educação de Surdos" - INES. Além dessa conquista, destacase também, como um marco para educação de surdos, a criação da Lei no 10.436, de 24 de Abril de 2002, que estabelece o reconhecimento da LIBRAS como a língua oficial utilizada pelas comunidades Surdas. Dessa forma, a formação de professores em libras é fundamental para atingir o objetivo da lei. Contudo, ainda é necessário que seja aprimorado o ensino de professores em libras, que apesar de existir 55 cursos de graduação e 375 de pósgraduação, são considerados poucos, devido a enorme demanda.
\end{abstract}

Palavras-chave: pedagogia, formação de professores em libras, ensino para surdos

\section{The Education of Deaf: Teacher Training nn the Brazilian Language of Signs (Libras)}

\begin{abstract}
The objective of this research was to identify, describe and analyze the scientific articles on the importance of deaf education in teacher education. A bibliographic review was carried out in the databases of scientific journals, technical notes and monographs, dissertations and theses, in Programs of Graduation in Pedagogy and Post-Graduation in Letters/Libras, with time base between 1999 and 2017. After the investigation of literature review and content reading, it was concluded that education for the deaf was conquered with a lot of struggle, especially regarding prejudice, because for a long time the deaf were considered sick people and motivators of shame within the family and society, with that, it was common to find an abandoned deaf. It stands out as the first school of the deaf, founded in Brazil, the "Imperial Institute of the Deaf-Mutes", currently, "National Institute of Education of the Deaf" - INES. In addition to this achievement, the creation of Law $\mathrm{N}^{\circ} 10.436$ of April 24, 2002, which establishes the recognition of LIBRAS as the language used by the deaf communities as the guarantee of inclusion is also highlighted as a milestone for the education of the deaf. However, it is still necessary to improve the teaching of teachers in pounds, which despite exacerbating 55 undergraduate and 375 graduate courses, are considered few because of the huge demand.
\end{abstract}

Keywords: pedagogy, teacher training in pounds, teaching for the deaf

\footnotetext{
1 Graduanda do curso de Licenciatura em Pedagogia, Faculdade de Ciências Humanas do Sertão Central - Fachusc, Email:andreasa2014@hotmail.com

2 Professora do curso de Licenciatura em Pedagogia, Faculdade de Ciências Humanas do Sertão Central - Fachusc, Email:lelamenezesluiza@yahoo.com.br

${ }^{3}$ Intérprete de Libras, Instituto Federal de Educação, Ciências e Tecnologia do Sertão Pernambucano - IFSPE. E-mail: alinemh22@hotmail.com
}

199 Id on Line Rev. Mult. Psic. V.11, N. 38. 2017 - ISSN 1981-1179

Edição eletrônica em http://idonline.emnuvens.com.br/id 


\section{Introdução}

A educação inclusiva no Brasil é marcada por preconceitos, lutas e conquistas. Antes da criação da língua de sinais, a comunicação com os surdos era muito complexa, pois em geral, a sociedade não sabia a língua de sinais e achava "feio" fazer "gesto" ou "mímica" como forma de comunicação e, consequentemente, não aceitavam a língua de sinais como a primeira língua dos surdos (MONTEIRO, 2006).

Para tanto, os surdos tinham a necessidade de se comunicar, e o uso dos sinais eram cada vez mais utilizados entre eles. Esses sinais são formados pela combinação do movimento das mãos e um formato definido em um determinado espaço e em uma parte do corpo ou num espaço delimitado ao corpo (COSTA, 2012).

Os sinais foram passando por diversos processos de mudança até atingir um padrão de comunicação. No Brasil, a língua oficial para os surdos é regulamentada pela Lei $\mathrm{n}^{\circ} 10.436$, de 24 de abril de 2002, ou, lei da Língua Brasileira de Sinais, ou somente Libras. A criação dessa lei foi considerada como um marco na educação dos surdos.

Dessa forma, essa Lei obriga a criação de cursos de licenciatura para a formação de professores de Libras. Se de um lado a lei indica a obrigatoriedade das instituições a oferecerem o ensino de Libras como disciplina curricular em todos os cursos de licenciatura nas diferentes áreas do conhecimento por outro, cria uma situação um tanto quanto conflitante: a falta de profissionais devidamente capacitados para atuarem na docência superior para o ensino de Libras. (MELO, 2012, p.3)

Um dos desafios fundamentais que emergem da proposta de escola inclusiva é a formação do professor, que para Fávero (2009) é justamente o reflexo do sucesso no ensino de Libras. Pois, é necessário que haja uma interação prática entre o professor e o aluno surdo, onde ensinar Libras, não significa simplesmente transmitir o conteúdo, mas sim, internalizar dentro do aluno a assimilação disciplinar proposto em sala de aula.

Por essa razão, a formação de professores e as inter-relações entre a teoria e a prática são fundamentais para um diálogo dinâmico e permanente. No Brasil, existem diversos cursos de graduação e pós-graduação em Libras, porém, o que se pode observar é que, muitos deles são à distância, o que afeta diretamente a relação prática entre professores e alunos. 
Além disso, é visível observar que os professores de Libras, são comumente confrontado com obstáculos que acabam por afetar a qualidade do ensino e da aprendizagem em Libras, seja pelo professor, como também pelo aluno surdo.

Foi pensando nessa temática que justificou a elaboração dessa obra. Assim, o objetivo desse trabalho foi analisar a educação de surdos na formação de professores na Língua Brasileira de Sinais (LIBRAS).

\section{Metodologia}

Trata-se de um estudo de revisão bibliográfica realizado entre os meses de junho a agosto de 2017, por meio de artigos científicos e notas técnicas, publicados em revistas relacionadas ao estudo em Libras, bem como partes de monografias, dissertações e teses em Programas de graduação em Pedagogia e Pós-Graduação em Libras, publicados entre os anos de 1999 a 2017.

Por se tratar de uma língua brasileira, específica para surdos, a revisão bibliográfica, concentrou-se exclusivamente em trabalhos nacionais, que embora, alguns artigos internacionais contemplassem a língua dos surdos, tiveram que ser excluídos por não comentar sobre a metodologia do ensino da língua brasileira de sinais.

Para a busca dos trabalhos, foram utilizados como palavras chaves os descritores: História na educação dos surdos, Surdez na educação brasileira, Formação de professores de Libras, Avanços no ensino de Libras e Obsetáculos enfrentados pelos professores de Libras.

\section{Breve história da educação dos surdos}

Compreender o passado é fundamental para interpretar o presente e nortear os caminhos para o futuro. A história da educação dos surdos foi baseada em preconceitos, lutas e conquistas. Noutro tempo á descoberta do Brasil, não existia escolas especializadas para deficientes, em especial, os surdos. Até o final do século $\mathrm{XV}$, os surdos eram considerados ineducáveis (CIBELERARIS, 2012). 
Esse pensamento retrograda, criado pela sociedade, baseava-se em castigos divínos. Antigamente, pessoas com deficiência física era explicadas como algo demonizado, como uma punição e/ou uma consequência de culpa (GARBE, 2012). Além disso, a surdez era confundida também como pessoas de inteligência limitadas. Em casos piores, como na antiguidade chinesa, crianças surdas eram atiradas ao mar; já os gauleses, sacrificavam-as em oferta aos deuses; em Atenas, eram simplismente rejeitadas pelas próprias famílias e abandonadas em locais públicas e/ou nos campos.

Como a surdez invibializa o principal meio de comunicação entre pessoas por meio da linguagem oral-auditiva, logo, foi observado que os surdos poderiam se comunicar através de sinais, diferentes das línguas oralizáveis (FERNANDES, 1999).

No ano de 1644, em Londres, foi lançado o primeiro livro que abordava a língua de sinais, chamado de Chirologia ou a língua natural da mão, de autoria de John Bulwer, o qual o autor acreditava que a língua de sinais era universal e icônica, pois os sinais reproduziam os objetos reais, não havendo a imaterialização (RAMOS, 2017).

No Brasil, o ensino para surdos iniciou-se na época Impérial, o qual foi fundado duas instituições: o Imperial Instituto dos meninos cegos, em 1854, atual Instituto Benjamim Constant, e o Instituto dos Surdos mudos, em 1857, hoje o moderno Instituto Nacional da Educação de surdos - INES, ambos na cidade do Rio de Janeiro (COUTO; RUBIO, 2014).

Atualmente o Instituto Nacional da Educação de surdos - INES é considerado um centro de auto padrão para atendimentos a educação de surdos no Brasil e várias matérias são desenvolvidas nessa instituição.

Por essa razão, o Rocha. (2010, p.33) destaca que INES é considerado uma referência nacional na educação de surdos conforme relata abaixo:

INES foi fundado há 152 anos e a presença de narrativas ligadas à memória faz parte da cultura institucional. A marca de sua longa história é muito forte na instituição, embora, contraditoriamente, a atenção com a memória oral seja mais relevante do que com a memória escrita. Muito se perdeu de fontes documentais matérias, por diversas razões que não cabem aqui serem discutidas (ROCHA, 2010, p.33).

Porém, no ano de 1880, durante o Congresso de Professores de Surdos em Milão, onde foi debatido e avaliado o "melhor método" para a educação do surdo, dentre elas, destacou-se a língua de sinais, o oralismo ou a mista (MOURA, 2000). Após a votação para definir qual método para educação do surdo, concluiram que o método oral seria o mais adequado, pois, 
para os professores daquela época, esse método tinha como objetivo, ensinar os surdos a falar e fazer leitura labial.

Após esse Congresso, ficou decidido em diversos países, inclusive no Brasil, aplicado ao Instituto dos Surdos Mudos, a proibição do uso da Língua de Sinais, para não desfazer a habilidade de oralização dos surdos, método este classificado como capaz de destruir a fala das crianças.

Porém, no ano de 1990, após o fracasso do método oral de ensino para surdos, algumas escolas assumiram a proposta da educação bilíngue, onde a língua de sinais foi utilizada como a primeira língua e língua de instrução, sendo a língua portuguesa oral e/ou escrita, considerada como segunda língua para os surdos (KUCHENBECKER; THOMA, 2011). Em 24 de Abril de 2002, o governo brasileiro estabeleceu o reconhecimento da lígua brasileira de sinais (LIBRAS) como a língua utilizada pelas comunidades surdas como a garantia de inclusão, o que foi considerado um dos grandes avanços na educação dos surdos.

\section{Legislação inclusiva - A Lei de Libras (Língua Brasileira de Sinais)}

As línguas de sinais, ao contrário do que muitos pensam, não têm características universais, pois existem diversas línguas de sinais em outros países, como por exemplo, a Língua de Sinais Portuguesa, Americana, Francesa entre outras.

No Brasil, foi definida a língua Brasileira de Sinais, onde sua sigla é definida como Libras e são usadas por todas as comunidades surdas do país, com exceção da comunidade surda indígena que possui sua própria língua de sinais. As comunicações da língua de sinais ocorrem manualmente e são feitas por meio de gestos, além das expressões faciais.

A língua Brasileira de Sinais teve sua origem a partir da língua de sinais francesa, pelo professor Charles Michel de L’Eppe (1712-1789) no final do século XVIII. L’Eppe, teve um papel fundamental para divulgação e estabelecimento dessa língua no Brasil, onde, mesmo com todo o preconceito e luta, foi possível consolidar essa língua no país.

Anos após o trabalho do professor L’Eppe, o autor Gladis Knak Rehfeldt, escreveu um livro com título "Linguistics bases for the description of Brazilian Sign language", publicado no livro editado por Harry W. Hoemann, “The sign language of Brazil”, em 1981 o qual trás os avanços educacionais conquistados pela comunidade surda (QUADROS, 1999). 
Apesar dessa publicação, o Instituto Nacional de Surdos-Mudos (INSM) considera como o maior documento sobre a língua de sinais no Brasil, o Iconographia dos Signaes dos Surdos-Mudos, de 1873, escrito por Flausino José da Gama, um aluno surdo do (INSM) (RAMOS, 2003).

Apesar de toda essa coletânia de materias relacionados a Libras, precisava-se de uma oficialização por meio de uma legislação específica para essa língua no país. No ano de 2002, foi criada a sancionada a lei da Língua Brasileira de Sinais.

A legislação aplicada a Língua Brasileira de Sinais - Libras, é determinada pela a Lei $\mathrm{n}^{\circ}$ 10.436, de 24 de Abril de 2002, estabelece o reconhecimento da LIBRAS como a língua utilizada pelas comunidades Surdas como a garantia de inclusão, conforme expresso:

\footnotetext{
Art. $1^{\circ}$ - É reconhecida como instrumento legal de comunicação e expressão a Língua Brasileira de Sinais - LIBRAS e outros recursos de expressão a ela associada.

Parágrafo único - Entende-se como Língua Brasileira de Sinais - LIBRAS a forma de comunicação e expressão, em que o sistema linguístico de natureza visual-motora, com estrutura gramatical própria, formam um sistema linguístico de transmissão de ideias e fatos, originários de comunidades de pessoas surdas do Brasil.
}

A publicação dessa Lei mudou significativamente a história da educação dos surdos no Brasil, colocando o Brasil à frente de muitos países desenvolvidos, pelo seu compromisso e respeito a comunidade de surdo (MORI; SANDER, 2015). No entanto, mesmo com a regulamentação dessa lei, é possível encontrar no Brasil, preconceitos quanto à oportunidade de estudos, emprego e socialização em geral.

\section{Formação de professores para a educação inclusiva}

A partir da conhecida "Lei de LIBRAS", o Decreto 5.626/05, reflete na necessidade de formação linguística de professores em libras, seja na educação básica, ensino técnico e superior, de forma que possibilite um dinamismo de ensino entre os cursos, professores e alunos.

Em relatos de Strobel (2008, p. 102), a mesma considera que:

São poucos os professores que são habilitados para trabalhar com os alunos surdos em sala de aula. A maioria dos cursos de Pedagogia nas universidades não tinham estas 
especializações para esta área e somente agora salvo pelo decreto n. 5626, de 22 de dezembro de 2005 que dá obrigatoriedade das aberturas de cursos de Libras nestes cursos, as coisas podem melhorar (Strobel, 2008, p. 102).

Pelo fato da LIBRAS ser uma língua reconhecida pela legislação e sendo o principal método de comunicação e expressão das pessoas Surdas no Brasil, torna-se de suma importância a formação de docentes capacitados para essa área e que conheçam e façam uso deste sistema linguístico.

O aluno surdo, para compreender e aprender um determinado assunto em sala de aula depende da mediação do professor que, para isto, deve ter uma formação específica na temática e em libras para poder atuar na educação de surdos, (MARGALL, et al., 2006). Além disso, os professores precisam estar aptos para ensinar, sentindo-se seguros no que diz respeito à apropriação da língua de sinais como meio de comunicação com seus alunos surdos.

Dessa forma, concordamos com Martins et al (2006, p.20), quando expõe sobre a formação docente voltada para as práticas inclusiva:

\begin{abstract}
Para tanto, requer-se, especialmente, uma efetiva preparação de profissionais de educação, que proporcione um contínuo de desenvolvimento pedagógico e educacional, que resulte numa nova maneira de perceber e atuar com as diferenças de todos os alunos em classe. Preparação que os faça conscientes não apenas das características e potencialidades dos seus alunos, mas de suas próprias condições para ensiná-los em um ambiente inclusivo, assim como da necessidade de refletirem constantemente sobre a sua prática, a fim de modificá-la quando necessário (MARTINS et al., 2006, p.20).
\end{abstract}

Em análise de coleta de dados realizada no site e-MEC no mês de agosto de 2017, referente à graduação e pós-graduação em Libras (e-MEC, 2017), é possível chegar a um quantitativo de cursos de graduação e pós-graduação com capacitação em Libras, no Brasil.

Conforme podemos observar no Quadro 01, o qual apresenta as nomenclaturas dos cursos de graduação ofertados em todo território nacional, podemos concluir que no geral, existem 55 cursos de graduação classificados com as seguintes terminologias: Letra/Libras/ Português; Letras/ Língua Portuguesa e Libras; Letras/Português domínio em Libras; LetrasLibras/Língua Estrangeira; e Letras/Libras. Há um domínio da formação em Letras/Libras com um quantitativo de 42 cursos, seguido de Letras/Língua Portuguesa/ Libras com 08 cursos, Letras/Libras/ Português com 03 e Letras/ Português Domínio em Libras e Letras Libras/ Língua estrangeria, ambos com 01 curso, conforme destacado no quadro abaixo. 
Tabela 01. Cursos de Graduação com capacitação em Libras ofertados no Brasil

\begin{tabular}{lc}
\multicolumn{1}{c}{ Cursos de Graduação } & Quantidade \\
\hline Letras/ Libras & 42 \\
\hline Letras/Libras/ Português & 03 \\
\hline Letras/Língua Portuguesa/ Libras & 08 \\
\hline Letras/ Português Domínio em Libras & 01 \\
\hline Letras Libras/ Língua estrangeria & 01 \\
\hline \multicolumn{2}{c}{ Total de cursos } \\
\hline
\end{tabular}

Fonte: Sistema e-MEC, 2017

Em cursos de pós-graduação em Libras no Brasil por região, é possível observar no Quadro 02, que a região sudeste apresenta a maior oferta de cursos, com um quantitativo de 129 pós-graduações, seguido pela região Nordeste, com 116, Norte com 55, Sul com 49 e Centro Oeste com 26 cursos de pós-graduação em Libras.

Tabela 02. Cursos de Pós-Graduação em Libras ofertados no Brasil

\begin{tabular}{cc}
\hline Cursos de Pós-Graduação por Região & Quantidade \\
\hline Nordeste & 116 \\
\hline Sudeste & 129 \\
\hline Norte & 55 \\
\hline Sul & 49 \\
\hline Centro-Oeste & 26 \\
\hline Total de cursos & $\mathbf{3 7 5}$ \\
\hline
\end{tabular}

Fonte: Sistema e-MEC, 2017 


\section{Estudo de caso (Formandos e suas habilidades em Libras)}

Em trabalho realizado por Souza et al. (2014), o qual avaliaram por meio de um questionário, aplicado aos alunos licenciados de uma faculdade privada localizada no município de Quissamã/RJ, para atender a essa demanda de alunos com surdez. Os resultados apresentados quantificam que (52\%) dos formandos mostraram ter dificuldades em aprender a disciplina de libras. No que se refere a não apresentar dificuldades, (37\%) responderam que não, porém (11\%) julgaram-se indiferente em relação a esta afirmação, conforme destacado no Quadro 03 abaixo.

Quadro 03. Questionário sobre a discilplina de Libras

\begin{tabular}{lccc}
\hline \multicolumn{1}{c}{ Perguntas } & Sim (\%) & Não (\%) & $\begin{array}{c}\text { Prefere não responder } \\
(\%)\end{array}$ \\
\hline $\begin{array}{l}\text { Teve dificuldade em } \\
\text { ampreder Libras? }\end{array}$ & $(37 \%)$ & $(52 \%)$ & $(11 \%)$ \\
\hline $\begin{array}{l}\text { Se sente preparado } \\
\text { para atuar com a }\end{array}$ & $(16 \%)$ & $(77 \%)$ & $(7 \%)$ \\
Libras? & & $(32 \%)$ & $(48 \%)$ \\
\hline $\begin{array}{l}\text { Sabe se comunicar em } \\
\text { Libras? }\end{array}$ \\
\hline
\end{tabular}

Fonte: Souza et al. (2014)

Em trabalho realizado por Filho; Vitaliano, (2011), onde analisaram o processo de formação de professores em um programa de inclusão de alunos surdos no ensino médio ocorrido entre os anos de 2004 a 2006 em uma escola pública do município de Londrina/PR, chegaram aos seguintes relatos dos professores das mais diversas disciplinas, sobre seus conhecimentos em libras, conforme destacado no Quadro abaixo: 
Tabela 04. Diagnóstico inicial sobre o conhecimento acerca de Libras

\begin{tabular}{cl}
\hline Disciplinas & \multicolumn{1}{c}{ Relatos } \\
\hline Português & $\begin{array}{l}\text { "Somente alguns sinais da mão", ou, "sou completamente } \\
\text { leigo no assunto". }\end{array}$ \\
\hline & "Nunca trabalhei com crianças ou adolescentes. Não tenho \\
& conhecimento, mas a experiência com o $1^{\circ}$ ano está sendo \\
ótima. Preocupei-me no inicio, mas força de vontade da & turminha é fantástica, pois consigo explicar os cálculos com \\
matemática & meus meios gestos". \\
\hline História & voluntariamente, na igreja, no ministério de surdos", ou, \\
& "nunca convivi antes da situação presente com pessoas com \\
& tal dificuldade. O que conheço vem de filmes sobre o tema \\
& e de conversas com pessoas com mais informações". \\
\hline Física & "Pouco, ou quase nada". \\
\hline Geografia & "Nada". \\
\hline Artes & "Não muito, só sei meu nome". \\
\hline Inglês & "Nada". \\
\hline Sociologia & "Que existe diferentes graus de surdez; que existe uma \\
\hline linguagem diferente/própria de surdos; que a forma de \\
expressão escrita é diferenciada".
\end{tabular}

Fonte: Filho e Vitaliano, (2011), adaptado por Araújo, 2017

No entanto, contratar outro profissional para acompanhar o professor de Libras torna-se inviável para as instituições, que muitas vezes acabam optando por contratar um professor ouvinte que domine língua de sinais, em alguns casos, sem a devida competência linguística (REBOUÇAS, 2009).

\section{Obstáculos encontrados pelos professores de Libras}

Muitos professores em geral e em especial para os da educação inclusiva, no caso dessa obra, o ensino de Libras, se deparam com muitos obsetáculos no que se refere às condições desfavoráveis de trabalho no ensino dos surdos, o que afeta diretamente a qualidade do ensino. De acordo com Facion et al. (2008, p.145) os principais obstáculos encontrados pelos professores de Libras são: "a eficácia da metodologia aplicada; a falta de recursos e de infra- 
estrutura; as péssimas condições de trabalho; as jornadas de trabalho excessivas; os limites da formação profissional, o número elevado de alunos por sala de aula.

Também é fundamental que destacar que os materiais didáticos específicos, tais como: livros em língua de sinais e em língua portuguesa; computadores com acesso a internet e com software dicionário de LIBRAS, entre outros, são muitas vezes escassos nas escolas públicas do país. Hoje, o uso da tecnologia pelos professores e alunos em sala de aula, tem melhorado significativamente a qualidade do ensino. Porém, as limitações encontradas nas escolas, são evidentes. Dessa forma, é necessário que sejam criados novos investimentos por parte das políticas públicas para alavancar a qualidade do ensino inclusivo.

Outro obsetáculo encontrado pelo professor de Libras relaciona-se a diversidade do alunado, que muitas vezes, apresentam cultura diferente dos demais alunos, e para isso, é importante que se tenham uma equipe de profissionais que atuam com surdos, como pisicólogos, terapeutas, fonoaudiólogos etc.

\section{Considerações Finais}

Ao analisar as informações bibliográficas sobre a temática relacionada a educação dos surdos e a formação de professores em Libras, conclui-se que houve um processo de mudança significativa do olhar da sociedade em relação à questão do Surdo, sua língua, cultura e educação. Entretanto, ainda é um processo lento no contexto das políticas educacionais da sociedade brasileira.

Em razão da oferta de cursos pós-graduação em Libras, bem como as suas prerrogativas relacionada à educação inclusiva, muitos professores têm feito estas especializações no intuito de proprocionar um melhor conheciemento em Libras e atender as nessecidades dos alunos surdos com qualidade e eficiência, porém, percebe-se que as maiorias são de ensino a distância e muitas vezes são cursos basicamente teóricos, o que acaba por afetar a qualidade na aprendizagem do professor, bem como nas práticas em salas de aula.

É necessário disseminar as políticas públicas vontadas a educação inclusiva, por meio de capacitações de professores em libras, melhoria na estrutura de trabalho e remuneração acessível à profissão do professor em Libras. 


\section{Referências}

CIBELERARIS. HISTÓRIA DA LIBRAS (língua brasileira de sinais). Disponível em: $<$ https://adaptareincluir.wordpress.com/2012/12/26/historia-da-libras-lingua-brasileira-desinais/>. Acesso em: 05 ago. 2017.

COSTA, R. C. R. Proposta de Instrumento para a Avaliação Fonológica da Língua Brasileira de Sinais: FONOLIBRAS. 231 f. Dissertação (mestrado) - Universidade Federal da Bahia, Instituto de Letras, Salvador, 2012.

COUTO, L. F.; RUBIO, J. A. S. Libras: uma análise histórica na perspectiva da educação inclusiva. Revista Eletrônica Saberes da Educaçã, v.5, n.1, 2014.

e-MEC. Cadastro e-MEC de Instituições e Cursos de Educação Superior. Disponível em: <http://emec.mec.gov.br/> Acesso em: 09 de agos. 2017.

FACION, J. R. et.al. O papel do professor na educação inclusiva. In: FACION, José Raimundo (org.). Inclusão escolar e suas implicações. $2^{\mathrm{a}}$ edição, Curitiba, Ibpex, 2008.

FÁVERO, O. et al. (Org.) Tornar a educação inclusiva. Brasília: UNESCO, 2009.

FERNANDES, E. Teorias de Aquisição da linguagem. In: GOLDFELD, M. Fundamentos em fonoaudiologia. Rio de Janeiro: Guanabara Koogan, 1998.

FILHO, D. C.; VITALIANO, C. R. O processo de formação de professores em um programa de inclusão de alunos surdos no ensino médio. VII Encontro da Associação Brasileira de Pesquisadores em Educação Especial, p. 2890-2901, 2011.

GARBE, D. S. Acessibilidade às pessoas com deficiência física e a convenção internacional de Nova Iorque. Revista Unifebe, Balneário Camboriú, v.10, p. 95-104, 2012.

KUCHENBECKER, L. G.; THOMA, A. S. Examinar, enquadrar, adaptar o currículo e desenvolver a língua de sinais: estratégias de normalização de alunos surdos down em uma escola de surdos. Revista Educação Especial, Santa Maria, v. 24, n. 41, p. 347-362, 2011.

MARGALL, S. A. C.; HONORA, M.; CARLOVICH, A. L. A. A reabilitação do deficiente auditivo visando qualidade de vida e inclusão social. O Mundo da Saúde, v. 30, n.1, p. 123$128,2006$.

MARTINS, L. A. R. et al. (Orgs.). Inclusão: Compartilhando Saberes. $4^{a}$ Edição. Rio de Janeiro: Editora Vozes, 2006.

MELO, G. F.; OLIVEIRA, P. S. J. Ensino-aprendizagem de Libras: mais um desafio para a formação docente. R. Educ. Prof, v. 38, n. 3,p. 1-10,2012. 
MORI, N. N. R.; Sander, R. E. História da educação dos surdos no Brasil. Seminário de Pesquisa PPE, Universidade Estadual de Maringá, 2015.

QUADROS, R. (Org.). Estudos Surdos I - Série de Pesquisas. Rio de Janeiro: Arara Azul, 2006.

RAMOS, Clelia Regina. Libras: A Língua dos Sinais dos Surdos Brasileiros. EBOOKS, 2003.

RAMOS, C. R. LIBRAS: A Língua de Sinais dos Surdos Brasileiros. Disponível em <http://www.editora-arara-azul.com.br/pdf/artigo2.pdf>. acesso em 06 agos. 2017.

REBOUÇAS, L. S. A prioridade dos docentes surdos para ensinar a disciplina Língua Brasileira de Sinais (Libras) nas instituições de ensino superior após o decreto 5.626/2005. 2009. 171f. Dissertação de Mestrado - UFBA, Salvador, BA. 2009.

ROCHA, S. M. Antíteses, díades, dicotomias no jogo entre memória e apagamento presentes nas narrativas da história da educação de surdos: um olhar para o Instituto Nacional de Educação de Surdos (1856/1961). Tese (Doutorado em Educação) - Pontifícia Universidade Católica do Rio de Janeiro, Rio de Janeiro, 2009.

MONTEIRO, M. S. História dos movimentos dos surdos e o reconhecimento da libras no Brasil. Educação Temática Digital, Campinas, v.7, n.2, p.292-302, 2006.

SOUZA, C. H. M.; MANHÃES, F. C.; BATISTA, C. M. A.; PINTO, F. O. A perspectiva da libras na formação do professor: um caminho para a inclusão escolar. Revista Digital, v.19, $\mathrm{n}^{\circ}$ $191,2014$.

STROBEL, K. L. As imagens do outro sobre a cultura surda. 1 ed. Florianopólis: Editora UFSC, 2008. v. 1, p 118.

Como citar este artigo (Formato ABNT):

ARAÚJO, Andrea S.; MENEZES, Aurelania M de C.; ARAÚJO, Aline C. S. A Educação de Surdos: Formação de Professores na Língua Brasileira de Sinais (LIBRAS). Id on Line Revista Multidisciplinar e de Psicologia, 2017, vol.11, n.38, p.199-211. ISSN: 1981-1179.

Recebido: 22.010 .2017

Aceito: 25.10 .2017 